\title{
Modulation of the PLLA Morphology through Racemic Nucleation to Reach Functional Properties Required by 3D Printed Durable Applications
}

\author{
Doina Dimonie $^{1}\left(\mathbb{D}\right.$, Silvia Mathe ${ }^{2, *} \mathbb{C}$, Manuela Maria Iftime ${ }^{3}$, Daniela Ionita $^{3}$, Roxana Trusca ${ }^{4}$ \\ and Sorina Iftimie ${ }^{5}$ \\ 1 National Institute for Research and Development in Chemistry and Petrochemistry, \\ 202 Splaiul Independentei, 060021 Bucharest, Romania; ddimonie@yahoo.com \\ 2 Doctoral School "Applied Chemistry and Materials Science", Politehnica University of Bucharest, \\ 1-7 Gheorghe Polizu, 011061 Bucharest, Romania \\ 3 "Petru Poni" Institute of Macromolecular Chemistry, 41A Grigore Ghica Voda Alley, 700487 Iasi, Romania; \\ ciobanum@icmpp.ro (M.M.I.); dgheorghiu@icmpp.ro (D.I.) \\ 4 Department of Science and Engineering of Oxide Materials and Nanomaterials, Politehnica University \\ of Bucharest, 1-7 Gheorghe Polizu, 011061 Bucharest, Romania; truscaroxana@yahoo.com \\ 5 Department of Electricity and Magnetism, Solid-State Physics, and Biophysics, Faculty of Physics, \\ University of Bucharest, 405 Atomistilor, 077125 Magurele, Romania; sorina.iftimie@fizica.unibuc.ro \\ * Correspondence: mathe.silvia@yahoo.com
}

check for updates

Citation: Dimonie, D.; Mathe, S.; Iftime, M.M.; Ionita, D.; Trusca, R.; Iftimie, S. Modulation of the PLLA Morphology through Racemic

Nucleation to Reach Functional Properties Required by 3D Printed Durable Applications. Materials 2021, 14, 6650. https://doi.org/10.3390/ ma14216650

Academic Editor: Antonino Recca

Received: 11 October 2021

Accepted: 31 October 2021

Published: 4 November 2021

Publisher's Note: MDPI stays neutral with regard to jurisdictional claims in published maps and institutional affiliations.

Copyright: (c) 2021 by the authors. Licensee MDPI, Basel, Switzerland. This article is an open access article distributed under the terms and conditions of the Creative Commons Attribution (CC BY) license (https:// creativecommons.org/licenses/by/ $4.0 /)$.

\begin{abstract}
This paper presents an alternative for enhancing the durability of poly (L-lactide) (PLLA) by racemic nucleation following stereo-complexation with a selected poly (D-lactide) (PLDA). The compounds are obtained by melt blending of a PLLA grade, previously designed for 3D printing but with a low heat deflection temperature and impact resistance, with grades of PLDA differing in their molecular weight (Mw), D-lactide content (DS) and concentration. Our method considered how to reveal the racemic nucleation caused by stereo-complexation and its influence on functional properties. The FTIR study we performed showed that, depending on Mw, DS and concentration of the stereo-complexer (PDLA) used, bigger or smaller spectral changes can occur. The stereocomplexation was confirmed by the DSC analysis and, for the selected compound, by the POM, SEM, AFM microscopies, functional property and shapeability as 3D printing filaments. All the obtained results sustain the idea that, if a PLLA with $\mathrm{M}_{\mathrm{w}}$ of $4.5 \times 10^{4} \mathrm{~g} \cdot \mathrm{mol}^{-1}$ is modified with PDLA with a medium $\mathrm{M}_{\mathrm{w}}$ of $11.6 \times 10^{4} \mathrm{~g} \cdot \mathrm{mol}^{-1}$, medium DS of $4 \%$ and $1 \%$ concentration, a racemic nucleation is possible. It produces a racemic polylactic acid (PDLLA) with improved durability and good shapeability as 3D printing filaments. These results are explicable if the dependence of the intermolecular interactions appears between the PLLA and stereo-complexer PDLA. To enlarge the durable applicability of racemic polylactic acid (PDLLA), future research should identify other parameters controling the PLA stereo-complexing as the intensifying the mobility of the macromolecules, the finding of the optimal recemic cristalization window.
\end{abstract}

Keywords: PLA; stereo-complexing; racemic nucleation; functional properties; filament; 3D printing

\section{Introduction}

Poly(lactic) acid (PLA) is a biodegradable, biocompatible, compostable, semi-crystalline, bio-based thermoplastic aliphatic polyester, which has a relatively low cost, outstanding strength and a high elastic modulus. Its good melt processability makes it a significant alternative to the petrochemical-based polymers such as polypropylene (PP), polystyrene (PS) and polyethylene (PE). [1-4]. Despite its many advantages, PLA is a brittle polymer with a low thermal deformation temperature, poor toughness and low crystallization rates [5-10]. These disadvantages limit its applicability, particularly for long-life (durable) items, including for the 3D printed grades designed for the automotive industry [11] which 
need key characteristics such as high temperature melt processability, significant toughness and durability [12]. Durability is defined as the property of polymeric materials to withstand environmental stresses during its life time so that the material's performance not to be hindered [13]. Durability refers to those properties that can fail before the end of the item's lifetime. These properties depend on the degradation stresses characterizing each application. For example, if temperature resistance is the main requirement for a certain application, then the thermal properties level will be the main expression of durability. If during its lifetime the plastic item works under continuous mechanical stresses, then the mechanical properties will define its durability [13]. To design the PLA-based material's functional properties [14-17], including strong 3D printability and mainly considering polymer morphology [18], the following techniques are usually used: copolymerization [19], melt compounding with other polymers [20] and controlled crystallizations (in-mold annealing-under shear flow-through nucleation) [13,21-26]. Nucleation involves the formation, in a "controlled" manner and in the same volume unit, of more crystals with a smaller size, as in "spontaneous crystallization", which generates the changing of the morphology. Obtaining a desired morphology in a "controlled" pattern improves physical, mechanical and optical properties, as well as dimensional stability, output at melt processing and the cost-performance index [27]. Nucleation can be achieved following different mechanisms, either by using nucleation/clarifying agents or by stereo-complexing (racemic nucleation) $[13,27]$. The nucleant is a solid salt that remains solid at the compounding temperature, and its particles represent the points around which the crystals develop. The higher the number of nucleation nuclei (particles of nucleant), the more new crystals appear and the smaller their size upon appearance [13].

The stereo-complexation is the result of selective interactions between two enantiomers, which have the same composition but different three-dimensional configurations [27]. The driving force of PLA stereo-complexation is the hydrogen bonds established between the $-\mathrm{CH}_{3}$ and $\mathrm{O}=\mathrm{C}$ groups of the two enantiomers macromolecules. Following the formation of these secondary interactions, changes related to the adjacent functions to these groups also appear, namely the C-O-C or -C-O- linkages [28-31]. These interactions generate racemic nucleation with high rate and, therefore, the formation of a semi-crystalline morphology with small-sized crystallites represented by racemic or mixtures of racemic with a homopolymer type, spread into an amorphous matrix. [32-36] Compared to the parent polymers, the resulting racemic polylactic acid (PDLLA) has enhanced functional properties (mechanical strength, thermal and hydrolytic stability etc.) and therefore controlled durability [30-33,37,38].

The lactic acid contains an asymmetric optically active carbon, which produces two optical isomers-L-lactic acid (levo-rotatory) and D-lactic acid (dextro-rotatory) [35,36] and, consequently, the following enantiomers: poly (L-lactide) (PLLA), poly (D-lactide) (PDLA), meso poly (lactide) (meso-PLA) and racemic polylactic acid (PDLLA) [37]. The racemic nucleation of PLA in distinct conditions and blending ratios, by solution or melt blending, depends on its molecular weight (Mw) and D-lactide content (DS). It is known that the crystallinity decreases with the increase in the DS [39-41], but there are no data about the Mw influence or the optimal DS that favors stereo-complexation.

The goal of this paper is to find the proper molecular weight and D-lactide content of a PDLA that can be melt compounded with a PLLA to obtain a racemic polylactic acid with increased durability to be used as filaments for 3D printed items for long life applications in the automotive industry.

\section{Materials and Methods}

\subsection{Experiments}

In order to obtain PLLA for long-life 3D printed applications, the experimental program presented in Figure 1 was designed. Commercially available PLA grades with different molecular weights and D-lactide content (Table 1) were melt compounded using a common intensive melt-compounding rolling sequence (Brabender: $185^{\circ} \mathrm{C}-200{ }^{\circ} \mathrm{C}$, 
$100 \mathrm{rpm}$; laboratory roller: $100{ }^{\circ} \mathrm{C}-125^{\circ} \mathrm{C}, 25 \mathrm{rpm}$ ) to obtain new compounds shaped as rolling sheets of $0.6 \pm 0.05 \mathrm{~mm}$ thickness (composition as in Table 2).



Figure 1. Complete study design for achieving racemized PLLA with functional properties required by $3 \mathrm{D}$ printing automotive applications.

Table 1. Characteristics of the PLA grades used for stereo-complexation.

\begin{tabular}{|c|c|c|c|c|}
\hline PLA * Grade & Function & Code & $\mathrm{M}_{\mathrm{w}}, \mathrm{g} \cdot \mathrm{mol}^{-1}$ & D-Lactide Content, \% \\
\hline PLLA D $850^{2 *}$ & Base-PLLA & $\mathrm{P}_{\mathrm{b}}$ & $4.5 \times 10^{4 /}$ Low & $0.5 /$ Low \\
\hline PDLA D 3052 & Stereo-complexer & $\mathrm{P}_{\mathrm{m} 1}$ & $11.6 \times 10^{4 /}$ Middle & 4/Middle \\
\hline PDLA D 2003 & Stereo-complexer & $\mathrm{P}_{\mathrm{m} 2}$ & $18.04 \times 10^{4 /}$ High & 3.5/Middle \\
\hline PDLA D 4060 & Stereo-complexer & $\mathrm{P}_{\mathrm{m} 3}$ & $19 \times 10^{4 /}$ High & 12/High \\
\hline
\end{tabular}

* INGEO of Natura Works; ${ }^{2 *}$ Designed for 3D printing.

Table 2. The composition of the new stereo-complexed compounds (sc-compounds).

\begin{tabular}{|c|c|c|c|c|c|c|c|c|c|}
\hline \multirow{3}{*}{ Codes } & \multicolumn{9}{|c|}{ Blending Proportion for Getting Racemic Compounds, \% } \\
\hline & \multicolumn{3}{|c|}{$M^{*} \mathbf{M}_{\mathbf{w}}$ and $\mathbf{M}^{*} \mathrm{DS} *$} & \multicolumn{2}{|c|}{$\mathrm{H}^{*} \mathrm{M}_{\mathrm{w}}$ and $\mathrm{M}^{*} \mathrm{DS} *$} & \multicolumn{4}{|c|}{$H^{*} M_{w}$ and $H^{*} D^{*}$} \\
\hline & sc-1 & sc-2 & sc-3 & sc-4 & sc-5 & sc-6 & sc-7 & sc-8 & sc-9 \\
\hline$P_{b}$ & 95.24 & 80 & 66.66 & 80 & 66.66 & 99 & 95.24 & 90.91 & 80 \\
\hline $\mathrm{P}_{\mathrm{m} 1}$ & 4.76 & 20 & 33.33 & - & - & - & - & - & - \\
\hline $\mathrm{P}_{\mathrm{m} 2}$ & - & - & - & 20 & 33.33 & - & - & - & - \\
\hline$P_{\mathrm{m} 3}$ & - & - & - & - & - & 1 & 4.76 & 9.09 & 20 \\
\hline
\end{tabular}

$\mathrm{M}^{*}$ - medium; $\mathrm{H}^{*}$-high; $\mathrm{DS}^{*}$-D-lactide content.

\subsection{Characterization}

2.2.1. Chemical Structure and Thermal Behavior

To find the influence of racemic complexation on chemical structure and thermal behavior, the sc-compounds were firstly characterized by Fourier transform-infrared spectroscopy in the attenuated total reflectance mode (FTIR-ATR) and then by differential scanning calorimetry (DSC). Each selected sc-compound was characterized in depth, mainly by studying its crystallization behavior (polarized optical microscopy-POM), morphology (scanning electron microscopy-SEM), surface appearance (atomic force microscopyAFM), functional properties and shapeability as filaments for 3D printing.

For tracking the spectral changes characterizing the PLLA racemization, the following FTIR ranges have been studied: $3600-2800 \mathrm{~cm}^{-1}, 1850-1700 \mathrm{~cm}^{-1}, 1500-1000 \mathrm{~cm}^{-1}$ and $1000-700 \mathrm{~cm}^{-1}$ [42-45].

FTIR-ATR was carried out using Perkin Elmer Spectrum 100 equipment to record the FTIR spectra between 4000 and $650 \mathrm{~cm}^{-1}$. To obtain an optimal signal-to-noise ratio, 32 scans were performed. A clean, empty diamond crystal was used for the collection of the background spectrum.

To eliminate the sample's thermal history $[43,44]$, the DSC thermograms were recorded with 3 runs ( 2 heating and 1 cooling). The recording was performed on a DSC3 Mettler 
Toledo device, using the following procedure: first heating from 20 to $200{ }^{\circ} \mathrm{C}\left(10{ }^{\circ} \mathrm{C} / \mathrm{min}\right)$, cooling from 200 to $20{ }^{\circ} \mathrm{C}\left(2{ }^{\circ} \mathrm{C} / \mathrm{min}\right)$, second heating from 20 to $250{ }^{\circ} \mathrm{C}\left(10{ }^{\circ} \mathrm{C} / \mathrm{min}\right)$ and a 2 min isotherm between each segment. The crystallinity $(X)$ was calculated with the Equation (1), where the parameters represent: $\Delta \mathrm{H}_{\mathrm{m}}-$ melting enthalpy, $\Delta \mathrm{H}_{\mathrm{cC}}-$ cold crystallization enthalpy, $\Delta \mathrm{H}_{m}^{o}$-melting enthalpy of a $100 \%$ crystalline PLA $\left(93.1 \mathrm{~J} \cdot \mathrm{g}^{-1}\right.$ ) and $w_{P L A}-$ mass fraction of PLA in the compound $[44,45]$.

$$
\% X=\frac{\Delta \mathrm{H}_{\mathrm{m}}-\Delta \mathrm{H}_{\mathrm{cC}}}{\Delta \mathrm{H}_{m}^{o} \cdot w_{P L A}} \cdot 100 \% X=\frac{\Delta \mathrm{H}_{\mathrm{m}}-\Delta \mathrm{H}_{\mathrm{cc}}}{\Delta \mathrm{H}_{m}^{o} \cdot w_{P L A}} \cdot 100
$$

\subsubsection{Deep Characterization of Selected Blend}

The selected sc-compound was characterized in depth, mainly by studying its crystallization behavior (polarized optical microscopy-POM, Leica Microsystems Inc., Morrisville, NC, USA, morphology (scanning electron microscopy-SEM (Tescan, Brno-Kohoutovice, Czech Republic), surface appearance (atomic force microscopy-AFM (A.P.E Research, Trieste, Italy), functional properties and shapeability as filaments for 3D printing.

The POM was performed with a Leica DM 2500M optical microscope (Leica Microsystems Inc., Morrisville, NC, USA) equipped with an objective of 10X, Mettler Toledo FP82HT heating plate and FP 90 central Processor Microscope (Mettler-Toledo, Columbus, $\mathrm{OH}, \mathrm{USA})$. The temperature program used was as follows: heating $\mathrm{I}: 10^{\circ} \mathrm{C} / \mathrm{min}$; cooling I: $2{ }^{\circ} \mathrm{C} / \mathrm{min}$; heating II: $10^{\circ} \mathrm{C} / \mathrm{min}$; cooling II: $2{ }^{\circ} \mathrm{C} / \mathrm{min}$. The second cooling included an isothermal temperature program maintained until complete crystallization, with the program established using the DSC results and at the temperature at which the crystallization began.

SEM micrographs were taken with an equipment Tescan Vega type, XMU model, for both samples' transversal section and surface.

AFM analysis was conducted using an A.P.E Research equipment (A.P.E Research, Trieste, Italy), working in non-contact mode, on two scanning areas (3D) of $1 \mu \mathrm{m} \times 1 \mu \mathrm{m}$ and $5 \mu \mathrm{m} \times 5 \mu \mathrm{m}$. The following surface properties were calculated: mean square roughness (radical of the standard deviation from a considered basic plane, using $R M S^{2}=\frac{1}{L} \int_{0}^{L}\left(z^{2}\right) d x$, where $L$ is the length of the analyzed area and $z$ is the standard deviation) and the average roughness (the arithmetic mean of the absolute values of the standard deviation from a considered basic plane $\left.\left(R_{a}=\frac{1}{L} \int_{0}^{L}\lfloor z d x\rfloor\right)\right)$ [46].

The subsequent functional properties were also measured: Izod impact resistance according to ISO 180/2019 and heat deflection temperature (HDT) matching the ISO 75-1/2020. The shapeability as filaments of the selected sc-PLLA was determined on a laboratory Gottfert extruder with a laboratory line for calibration, pulling and filament rolling $\left(60^{\circ} \mathrm{C}, 165-180{ }^{\circ} \mathrm{C}, 135 \mathrm{rpm}\right)$.

\section{Results}

\subsection{FTIR Analysis}

The stereo-complexation was missing or was very small if the base-PLLA was stereocomplexed with PDLA with a high Mw $\left(18 \times 10^{4} \mathrm{~g} \cdot \mathrm{mol}^{-1}\right)$ and medium DS (3.5\%), or with PDLA with a high Mw $\left(19 \times 10^{4} \mathrm{~g} \cdot \mathrm{mol}^{-1}\right)$ and high DS $(12 \%)($ Table 3$)$. 
Table 3. The absorbance of the compounds resulting from stereo-complexing of base-PLLA with PDLA with a high $\mathrm{M}_{\mathrm{W}}$ (sc-4, sc-5, Pb, Pm2), and high Mw and high DS (sc-6, sc-7, sc-8, sc-9, Pb, Pm3) (Mw and DS according to Table 1 and blends compositions as in Table 2).

\begin{tabular}{|c|c|c|c|c|c|c|c|c|c|c|}
\hline \multirow{2}{*}{ FTIR Range } & \multirow{2}{*}{$\begin{array}{c}\text { Wavelength, } \\
\mathrm{cm}^{-1}\end{array}$} & \multirow{2}{*}{$\begin{array}{c}\text { Absorbance } \\
\mathbf{P}_{\mathbf{b}}\end{array}$} & \multicolumn{3}{|c|}{ Absorbance, $\mathrm{H}^{*} \mathrm{M}_{\mathrm{w}}$ and $\mathrm{M}^{*} \mathrm{DS}^{*}$} & \multicolumn{5}{|c|}{ Absorbance, $\mathrm{H}^{*} \mathrm{M}_{\mathrm{w}}$ and $\mathrm{H}^{*} \mathrm{DS}^{*}$} \\
\hline & & & sc-4 & sc-5 & $\mathbf{P}_{\mathrm{m} 2}$ & sc-6 & sc-7 & sc-8 & sc-9 & $\mathbf{P}_{\mathrm{m} 3}$ \\
\hline \multirow{3}{*}{$3600-2800 \mathrm{~cm}^{-1}$} & 2996 & 0.028 & 0.036 & 0.028 & 0.033 & 0.015 & 0.025 & 0.033 & 0.012 & 0.025 \\
\hline & 2945 & 0.029 & 0.035 & - & 0.034 & 0.016 & 0.031 & 0.035 & 0.011 & 0.027 \\
\hline & 2851 & 0.025 & 0.01 & 0.035 & 0.018 & 0.007 & 0.02 & 0.01 & - & 0.01 \\
\hline $1850-1660 \mathrm{~cm}^{-1}$ & 1747 & 0.45 & 0.68 & 0.46 & 0.6 & 0.22 & 0.37 & 0.65 & 0.14 & 0.45 \\
\hline \multirow{3}{*}{$1480-1300 \mathrm{~cm}^{-1}$} & 1452 & 0.13 & 0.16 & 0.13 & 0.15 & 0.08 & 0.11 & 0.15 & 0.05 & 0.11 \\
\hline & 1364 & 0.12 & 0.125 & 0.11 & 0.13 & 0.05 & 0.085 & 0.13 & 0.04 & 0.08 \\
\hline & 1306 & 0.045 & 0.065 & 0.055 & 0.07 & - & 0.06 & 0.05 & - & 0.065 \\
\hline \multirow{3}{*}{$1275-1000 \mathrm{~cm}^{-1}$} & 1180 & 0.42 & 0.6 & 0.48 & 0.55 & 0.20 & 0.375 & 0.60 & 0.13 & 0.39 \\
\hline & 1081 & 0.51 & 0.83 & 0.61 & 0.78 & 0.23 & 0.43 & 0.82 & 0.16 & 0.49 \\
\hline & 1042 & 0.37 & 0.48 & 0.38 & 0.48 & 0.19 & 0.31 & 0.45 & 0.12 & 0.32 \\
\hline
\end{tabular}

$\mathrm{M}^{*}$ - medium; $\mathrm{H}^{*}$-high; DS*-D-lactide content.

When the base-PLLA was compounded with PDLA with a medium molecular weight $\left(11.6 \times 10^{4} \mathrm{~g} \cdot \mathrm{mol}^{-1}\right)$ and medium DS (4\%) (sc-1 compound), the interactions appearing between the methyl $\left(-\mathrm{CH}_{3}\right)$ and carbonyl $(\mathrm{O}=\mathrm{C})$ groups resulted from the spectra presented in Figure 2. By relating to the absorption of the same functional groups from the basePLLA, the carbonyl absorption from $1747 \mathrm{~cm}^{-1}$ is $20 \%$ lower and its peak is $2 \mathrm{~cm}^{-1}$ shifted (Figure $2 \mathrm{~b}$,e). The $-\mathrm{CH}_{3}$ absorption from $2995 \mathrm{~cm}^{-1}$ is $25 \%$ smaller and its peak is $2 \mathrm{~cm}^{-1}$ shifted (Figure 2d). The $-\mathrm{CH}_{3}$ stretching from $1452 \mathrm{~cm}^{-1}$ is $23 \%$ lower (Figure 2f). The $-\mathrm{CH}_{3}$ absorption from $1360 \mathrm{~cm}^{-1}$ is $33.33 \%$ smaller and the peak is $4 \mathrm{~cm}^{-1}$ shifted (Figure $2 \mathrm{~g}$ ). The $-\mathrm{CH}_{3}$ stretching from $1042 \mathrm{~cm}^{-1}$ is $25 \%$ lower and the peak is $1 \mathrm{~cm}^{-1}$ shifted (Figure 2h).

Spectral changes were also observed regarding the bonds adjacent to the $-\mathrm{CH}_{3}$ and - $\mathrm{CO}$ groups, namely the $-\mathrm{C}-\mathrm{O}-\mathrm{C}$ and $-\mathrm{C}-\mathrm{O}-$ links (Figure 3 ). Additionally, the absorption from $1207 \mathrm{~cm}^{-1}$, assigned with the coupling of $\mathrm{C}-\mathrm{O}-\mathrm{C}$ stretching and $\mathrm{CH}_{3}$ rocking, is $32 \%$ smaller and shifted with $1 \mathrm{~cm}^{-1}$ (Figure $3 \mathrm{~b}$ ). The absorptions assigned with the $\mathrm{C}-\mathrm{O}-\mathrm{C}$ symmetric stretching also had the following changes: those from $1188 \mathrm{~cm}^{-1}$ are $26 \%$ smaller (Figure 3c), the one from $1081 \mathrm{~cm}^{-1}$ is $24 \%$ lower (Figure 3d), and the absorptions from $1058 \mathrm{~cm}^{-1}$ no longer exist. The absorption indicating the $-\mathrm{C}-\mathrm{O}-$ stretching at $1127 \mathrm{~cm}^{-1}$ is $30 \%$ smaller (Figure 3e) and those from $1175 \mathrm{~cm}^{-1}$, assigned with the $\mathrm{C}-\mathrm{O}-\mathrm{C}$ asymmetric stretching, are not present. 


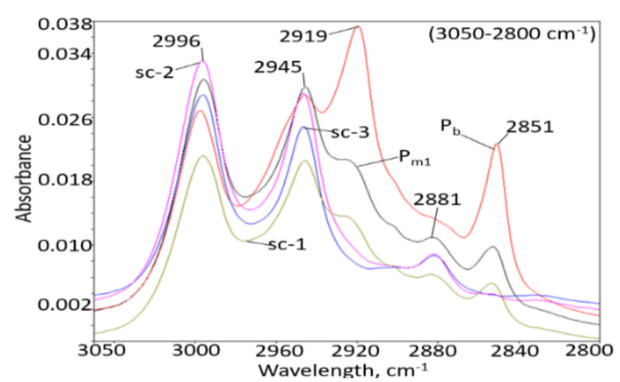

(a)

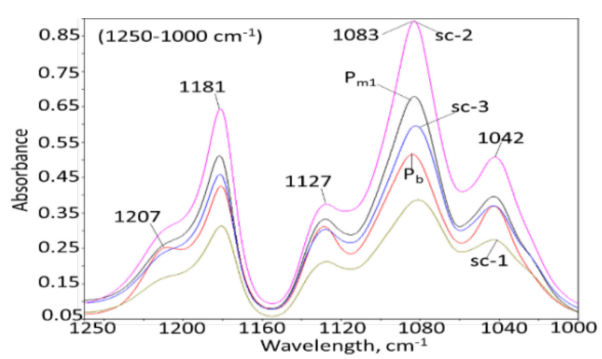

(c)

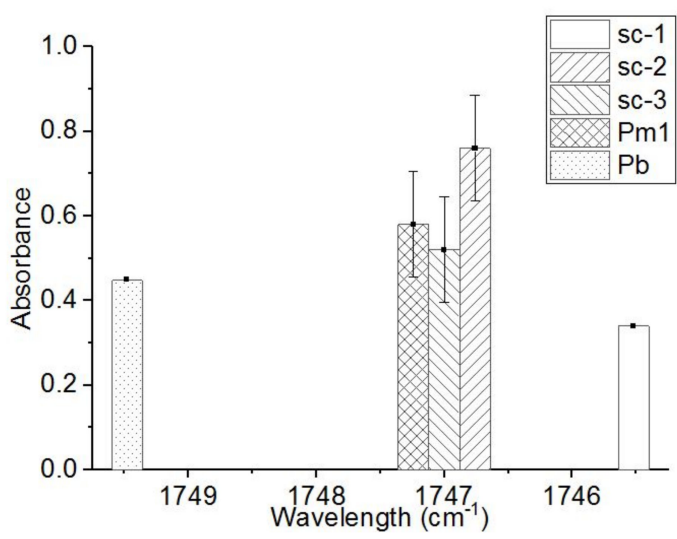

(e)

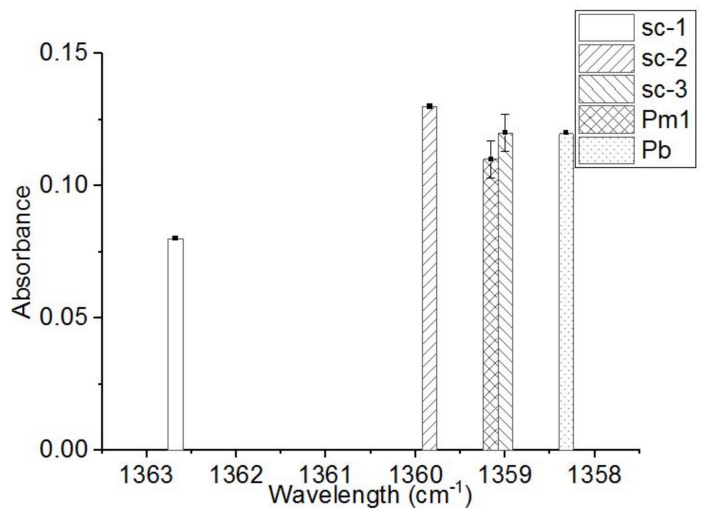

(g)

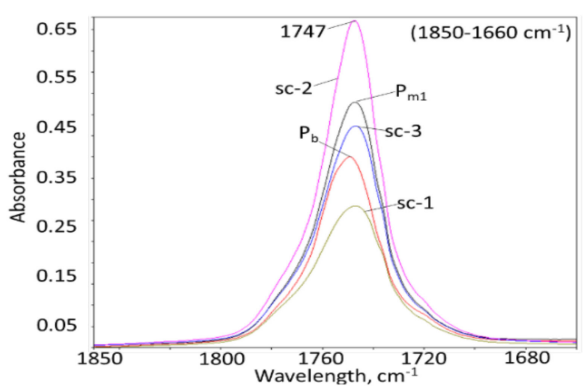

(b)

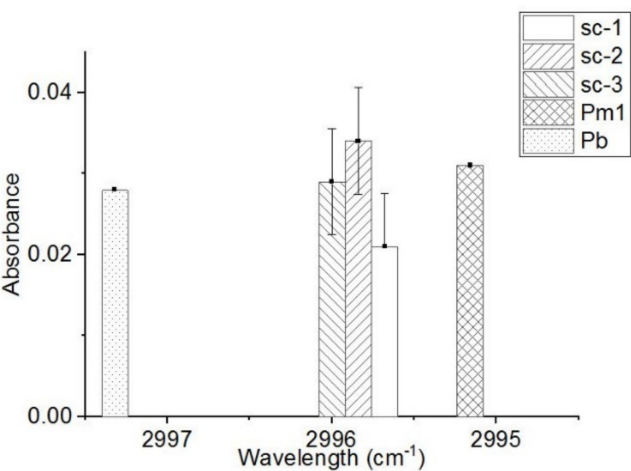

(d)

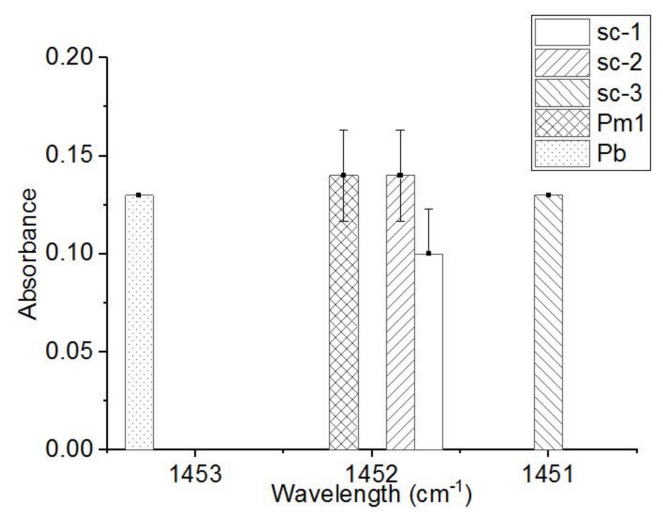

(f)

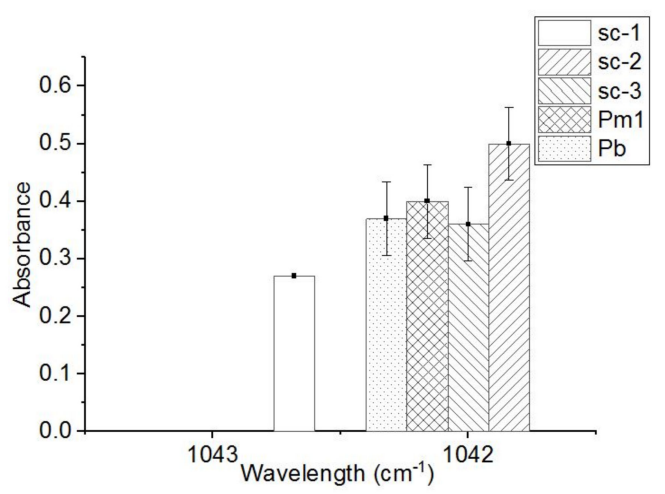

(h)

Figure 2. FTIR spectra of the sc-1, sc-2 and sc-3 compounds and those of the used PLA (base-PLLA and PDLA for stereocomplexing with medium $\mathrm{M}_{\mathrm{W}}$ and medium D-lactide content). (a) 3050-2800 $\mathrm{cm}^{-1}$ range; (b) $1850-1680 \mathrm{~cm}^{-1}$ range; (c) $1250-1000 \mathrm{~cm}^{-1}$ range; The absorbance at (d) $2995-2997 \mathrm{~cm}^{-1}$; (e) $1746-1749 \mathrm{~cm}^{-1}$ (f) $1451-1453 \mathrm{~cm}^{-1}$ (g) $1358-1363 \mathrm{~cm}^{-1}$; (h) $1042-1043 \mathrm{~cm}^{-1}$. 


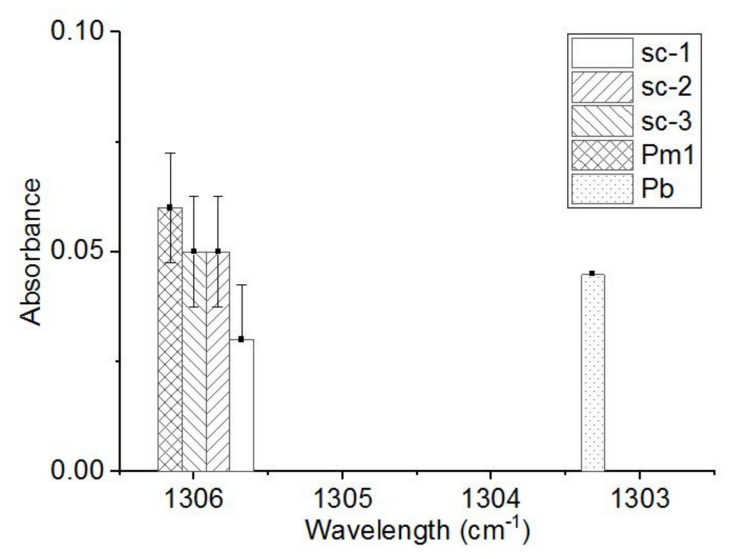

(a)

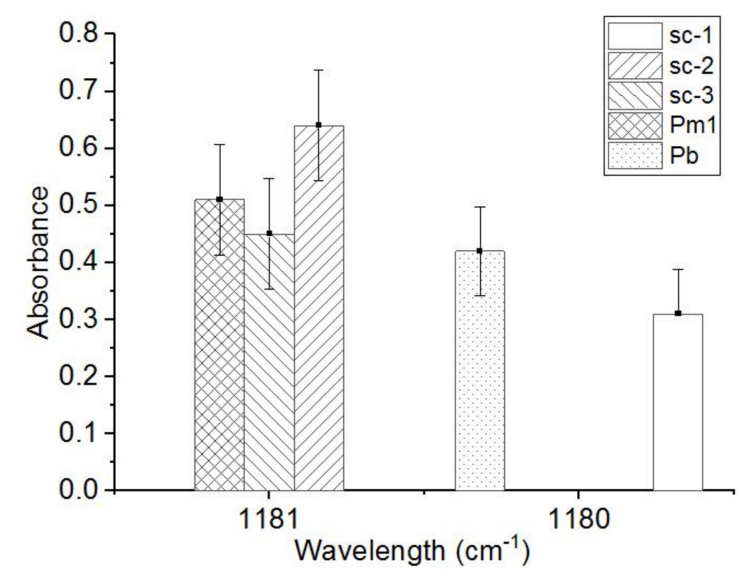

(c)

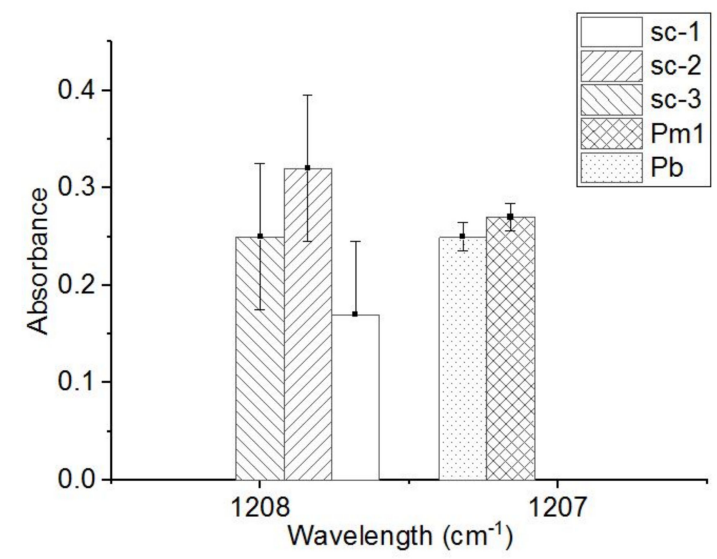

(b)

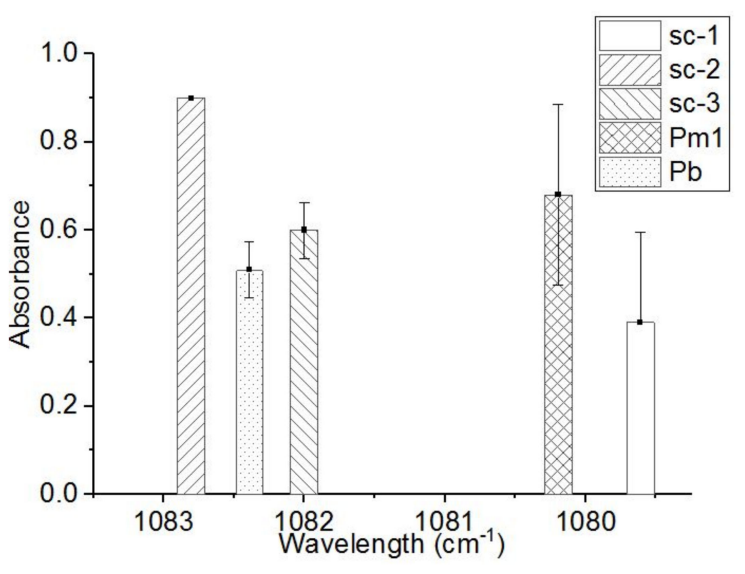

(d)

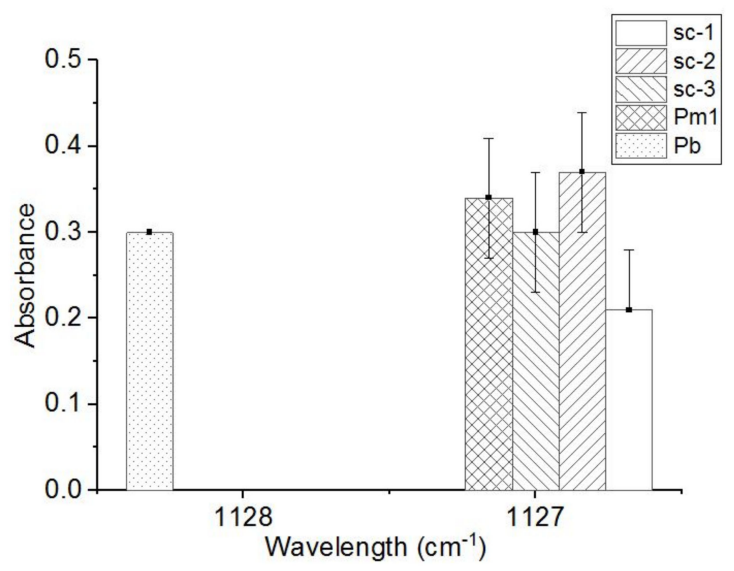

(e)

Figure 3. The FTIR absorptions in the $1128 \mathrm{~cm}^{-1}-1306 \mathrm{~cm}^{-1}$ of the sc-1, sc-2 and sc- 3 compounds; base-PLLA (Pb); and stereo-complexer PDLA with medium $\mathrm{M}_{\mathrm{w}}$ and medium DS (Pm1)). (a) 1303-1306 $\mathrm{cm}^{-1} ;(\mathbf{b}) 120-1208 \mathrm{~cm}^{-1}$; (c) $1180-1181 \mathrm{~cm}^{-1}$; (d) $1080-1083 \mathrm{~cm}^{-1}$; (e) $1127-1128 \mathrm{~cm}^{-1}$.

\subsection{DSC Analysis}

The compounds achieved through stereo-complexing the base-PLLA with PDLA with a high $\mathrm{M}_{\mathrm{W}}\left(18.04 \times 10^{4} \mathrm{~g} \cdot \mathrm{mol}^{-1}\right)$ and medium DS $(3.5 \%)$ have a glass transition lower with $1-3^{\circ} \mathrm{C}$ as the base-PLLA (Figure 4 , Table 4 ). Compared to the base polymer, these compounds have bimodal melting, which takes place in wider ranges moving to lower temperatures, and they have a $10-20 \%$ lower melting enthalpy (Figure $4 a$, Table 4 ). They 
also have a smaller crystallinity, crystallize in a wider range, shift to lower temperatures and have crystallization peaks at a couple ${ }^{\circ} \mathrm{C}$ lower than the base-PLLA (Figure $4 \mathrm{~b}$, Table 4). The same results were obtained in the case of stereo-complexing of base-PLLA with PDLA with high $\mathrm{M}_{\mathrm{W}}\left(19 \times 10^{4} \mathrm{~g} \cdot \mathrm{mol}^{-1}\right)$ and high DS (12\%) (Figure 5, Table 5).

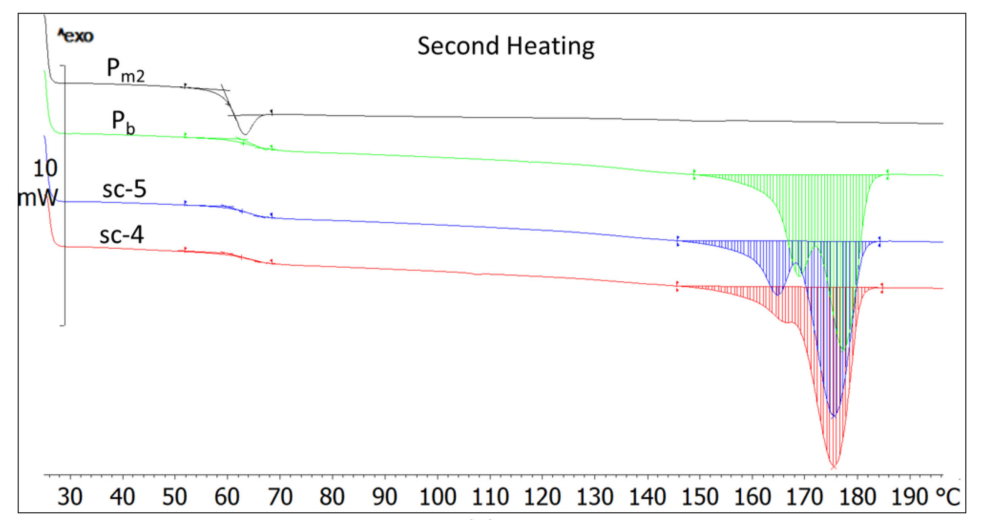

(a)

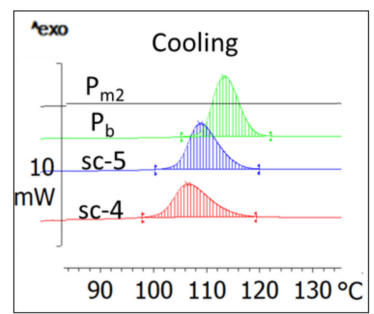

(b)

Figure 4. DSC thermograms of the sc- 4 and sc- 5 compounds and those of the blended polymers $\left(\mathrm{Pb}, \mathrm{P}_{\mathrm{m} 2}\right)$ after the second heating $\left(10{ }^{\circ} \mathrm{C} / \mathrm{min}\right)(\mathbf{a})$ and the cooling $\left(2{ }^{\circ} \mathrm{C} / \mathrm{min}\right)(\mathbf{b})$.

Table 4. DSC behavior of the sc- 4 and sc -5 compounds and those of the blended polymers $\left(\mathrm{P}_{\mathrm{b}}\right.$ and $\left.\mathrm{P}_{\mathrm{m} 2}\right)$.

\begin{tabular}{|c|c|c|c|c|c|c|c|c|c|}
\hline \multirow{2}{*}{ Sample } & \multirow{2}{*}{ DSC } & \multirow{2}{*}{$\begin{array}{c}\text { Glass Trans. } \\
t_{\mathrm{g},}{ }^{\circ} \mathrm{C}\end{array}$} & \multicolumn{3}{|c|}{ Crystallization (exo) } & \multicolumn{3}{|c|}{ Melting (endo) } & \multirow{2}{*}{$\begin{array}{c}\text { Cryst. } \\
\% \\
\end{array}$} \\
\hline & & & $\mathbf{t}_{\mathrm{c}},{ }^{\circ} \mathbf{C}$ & $\Delta \mathrm{Hc}, \mathrm{J} \cdot \mathrm{g}^{-1}$ & Range, ${ }^{\circ} \mathrm{C}$ & $t_{\mathrm{m}},{ }^{\circ} \mathrm{C}$ & $\Delta \mathrm{Hm}, \mathrm{J} \cdot \mathrm{g}^{-1}$ & Range, ${ }^{\circ} \mathrm{C}$ & \\
\hline \multirow{2}{*}{$\mathrm{P}_{\mathrm{b}}$} & Cooling & - & 113.5 & 38.4 & $125-105$ & - & - & - & - \\
\hline & Heating 2 & 65.7 & - & - & & 176.8 & 44.3 & $144-186$ & 47.7 \\
\hline \multirow{2}{*}{$\mathrm{P}_{\mathrm{m} 2}$} & Cooling & - & - & - & - & - & - & - & - \\
\hline & Heating 2 & 61.5 & - & - & - & - & - & - & - \\
\hline \multirow{2}{*}{ sc-4 } & Cooling & - & 106.6 & 32.2 & $120-98$ & - & - & - & - \\
\hline & Heating 2 & 53.6 & - & - & - & 175 & 38.1 & 146-185 & 40.9 \\
\hline \multirow{2}{*}{$\mathrm{sc}-5$} & Cooling & - & 108.9 & 34.1 & $121-100$ & - & - & - & - \\
\hline & Heating 2 & 63.6 & - & - & & 175 & 35.5 & $146-185$ & 38.2 \\
\hline
\end{tabular}

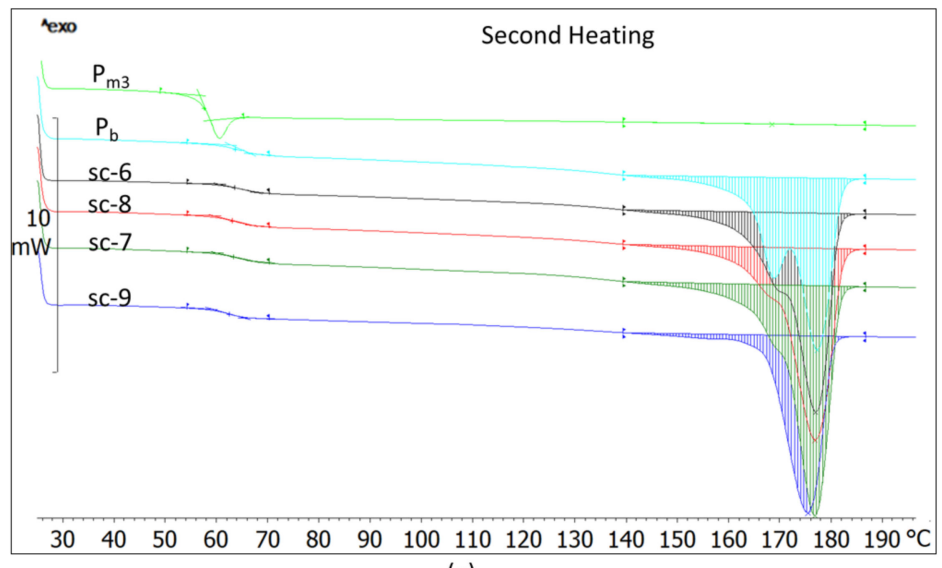

(a)

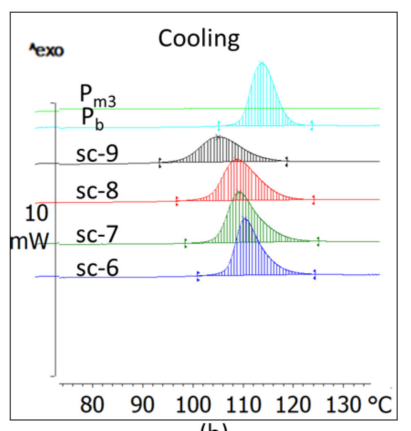

(b)

Figure 5. DSC thermograms of the sc-6, sc-7, sc- 8 and sc- 9 compounds and those of the compounded PLA grades $\left(\mathrm{P}_{\mathrm{b}}, \mathrm{Pm}_{3}\right)$ after second heating $\left(10^{\circ} \mathrm{C} / \mathrm{min}\right)(\mathbf{a})$ and after cooling $\left(2{ }^{\circ} \mathrm{C} / \mathrm{min}\right)(\mathbf{b})$. 
Table 5. DSC behavior of the sc-6, sc-7, sc- 8 and sc- 9 compounds and of the blended PLA grades $\left(\mathrm{P}_{\mathrm{b}}\right.$ and $\left.\mathrm{P}_{\mathrm{m} 3}\right)$.

\begin{tabular}{|c|c|c|c|c|c|c|c|c|c|}
\hline \multirow{2}{*}{ Sample } & \multirow{2}{*}{ DSC } & \multirow{2}{*}{$\begin{array}{c}\text { Glass Trans. } \\
t_{\mathrm{g}},{ }^{\circ} \mathrm{C}\end{array}$} & \multicolumn{3}{|c|}{ Crystallization (exo) } & \multicolumn{3}{|c|}{ Melting (endo) } & \multirow{2}{*}{$\begin{array}{c}\text { Cryst. } \\
\%\end{array}$} \\
\hline & & & $\mathbf{t}_{\mathrm{c},},{ }^{\circ} \mathrm{C}$ & $\Delta \mathrm{Hc}, \mathrm{J} \cdot \mathrm{g}^{-1}$ & Range, ${ }^{\circ} \mathrm{C}$ & $t_{m},{ }^{\circ} \mathrm{C}$ & $\Delta \mathrm{Hm}, \mathrm{J} \cdot \mathrm{g}^{-1}$ & Range, ${ }^{\circ} \mathrm{C}$ & \\
\hline \multirow{2}{*}{$\mathrm{P}_{\mathrm{b}}$} & Cooling & - & 113.5 & 38.4 & $125-105$ & - & - & - & - \\
\hline & Heating 2 & 65.7 & - & - & & 176.8 & 44.3 & 144-186 & 47.7 \\
\hline \multirow[b]{2}{*}{$\mathrm{P}_{\mathrm{m} 3}$} & Cooling & - & - & - & - & - & - & - & - \\
\hline & Heating 2 & 58.9 & - & - & - & - & - & - & - \\
\hline \multirow[b]{2}{*}{ sc-6 } & Cooling & - & 110.1 & 36.3 & $122-100$ & - & - & - & - \\
\hline & Heating 2 & 64.7 & - & - & - & 176.5 & 47.8 & 144-186 & 51.4 \\
\hline \multirow[b]{2}{*}{ sc-7 } & Cooling & - & 108.9 & 35.8 & $122-98$ & - & - & - & - \\
\hline & Heating 2 & 64.1 & - & - & - & 176.2 & 48.2 & $144-186$ & 51.9 \\
\hline \multirow{2}{*}{ sc- 8} & Cooling & - & 108.5 & 35.2 & $122-96$ & - & - & - & - \\
\hline & Heating 2 & 63.4 & - & - & - & 176.3 & 44.5 & 144-186 & 47.9 \\
\hline \multirow{2}{*}{ sc- 9} & Cooling & - & 104.7 & 31.2 & 118-92 & - & - & - & - \\
\hline & Heating 2 & 62 & - & - & - & 175 & 38.9 & 144-186 & 41.8 \\
\hline
\end{tabular}

These result show that if the base-PLLA is modified with PDLA with a high Mw and medium DS, or with a high Mw and high DS PDLA, then the morphological order of the resulting blends is significantly decreased. Considering the complete lack of stereocomplexing interactions between the base-PLLA and these two PDLA grades, proved by the FTIR spectra, the decreased morphological order of their compounds is explainable.

Unlike the compounds described above, those achieved by stereo-complexing the base-PLLA with PDLA with a medium $\mathrm{M}_{\mathrm{w}}\left(11.6 \times 10^{4} \mathrm{~g} \cdot \mathrm{mol}^{-1}\right)$ and medium DS (4\%) have different thermal behavior (Figures 6 and 7 , Table 6 ). The sc- 1 compound has a glass transition almost similar to that of the base-polymer (Table 6) and melts in a mono-modal homogenous way unlike the bi-modal melting of the base-PLLA (Figures $6 \mathrm{a}$ and 7a). The crystallization occurs narrowly and highly with a $7-12{ }^{\circ} \mathrm{C}$ temperature range as the basePLLA, which means that the crystallites are smaller and regular in size, and they do not contain or have very few defects [47]. The compounds' crystallinity is almost $7 \%$ greater considering the base-PLLA, the crystallinity, how the crystallization enthalpy increased by almost $6 \mathrm{~J} \cdot \mathrm{g}^{-1}$ (Table 6 ) and the crystallization's $6-10 \%$ temperature increase (Figures $6 \mathrm{~b}$ and $7 \mathrm{~b}$, Table 6).

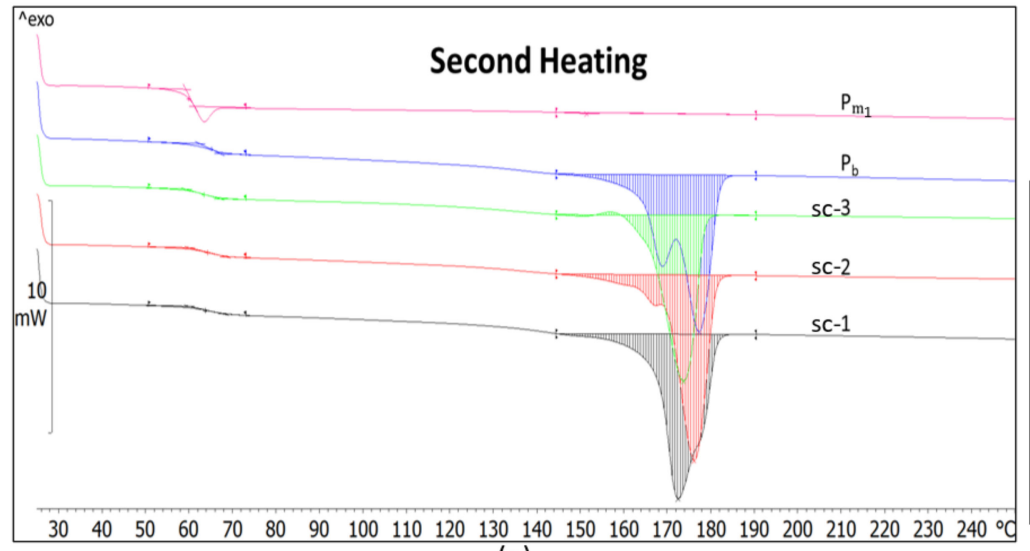

(a)

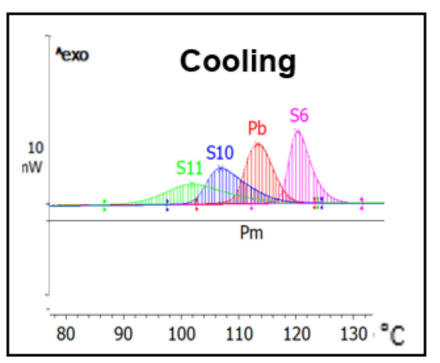

(b)

Figure 6. DSC thermograms of the sc-1, sc-2 and sc-3 compounds and of the blended PLA grades $\left(\mathrm{P}_{\mathrm{b}}, \mathrm{Pm}_{1}\right)$ after the second heating $\left(10^{\circ} \mathrm{C} / \mathrm{min}\right)(\mathbf{a})$ and cooling $\left(2{ }^{\circ} \mathrm{C} / \mathrm{min}\right)(\mathbf{b})$. 
Table 6. DSC behavior of the sc-1, sc-2 and sc- 3 compounds and of the blended polymers $\left(\mathrm{P}_{\mathrm{b}}\right.$ and $\left.\mathrm{P}_{\mathrm{m} 1}\right)$.

\begin{tabular}{|c|c|c|c|c|c|c|c|c|c|}
\hline \multirow{2}{*}{ Sample } & \multirow{2}{*}{ DSC } & \multirow{2}{*}{$\begin{array}{c}\text { Glass Trans. } \\
t_{\mathrm{g}},{ }^{\circ} \mathrm{C}\end{array}$} & \multicolumn{3}{|c|}{ Crystallization (exo) } & \multicolumn{3}{|c|}{ Melting (endo) } & \multirow{2}{*}{$\begin{array}{c}\text { Cryst. } \\
\%\end{array}$} \\
\hline & & & $\mathbf{t}_{\mathrm{c},},{ }^{\circ} \mathrm{C}$ & $\Delta \mathrm{Hc}, \mathrm{J} \cdot \mathrm{g}^{-1}$ & Range, ${ }^{\circ} \mathrm{C}$ & $t_{m},{ }^{\circ} \mathrm{C}$ & $\Delta \mathrm{Hm}, \mathrm{J} \cdot \mathrm{g}^{-1}$ & Range, ${ }^{\circ} \mathrm{C}$ & \\
\hline \multirow{2}{*}{$\mathrm{P}_{\mathrm{b}}$} & Cooling & - & 113.5 & 38.4 & $125-105$ & - & - & - & - \\
\hline & Heating 2 & 65.7 & - & - & - & 176.8 & 44.3 & 144-186 & 47.7 \\
\hline \multirow{2}{*}{$\mathrm{P}_{\mathrm{m} 1}$} & Cooling & - & - & - & - & - & - & - & - \\
\hline & Heating 2 & 61.7 & - & - & - & - & - & - & - \\
\hline \multirow{2}{*}{$\mathrm{sc}-1$} & Cooling & - & 120.4 & 44.2 & $130-113$ & - & - & - & - \\
\hline & Heating 2 & 64.4 & - & - & - & 172 & 48.4 & 144-186 & 52.1 \\
\hline \multirow{2}{*}{$\mathrm{sc}-2$} & Cooling & - & 107 & 35 & $122-96$ & - & - & - & - \\
\hline & Heating 2 & 60.3 & - & - & - & 175.6 & 43.1 & 144-186 & 46.4 \\
\hline \multirow{2}{*}{$\mathrm{sc}-3$} & Cooling & - & 101.9 & 31 & $122-88$ & - & - & - & - \\
\hline & Heating 2 & 63.1 & - & - & - & 173.2 & 40.8 & 144-186 & 43.8 \\
\hline
\end{tabular}

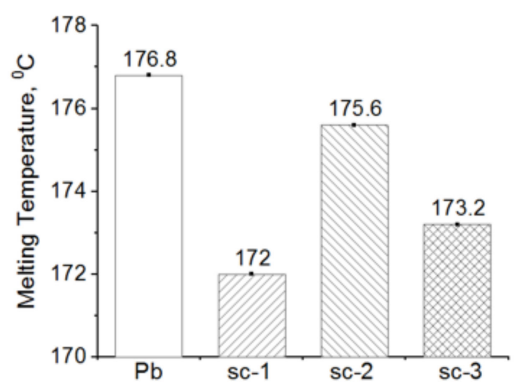

(a)

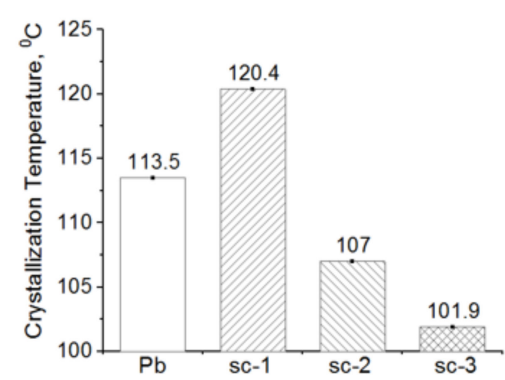

(b)

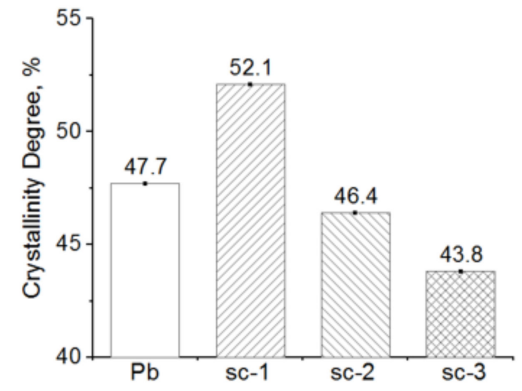

(c)

Figure 7. Thermal properties of the sc-1, sc-2 and sc-3 compounds vs. base-PLLA: melting temperature (a), crystallization temperature (b) and crystallization degree (c).

If in the case of the sc- 1 compound-which contains small amount of stereo-complexera certain morphological ordering effect was found, the same was not observed with a larger quantity. As the crystallinity and the crystallization temperature values revealed, the thermal behavior of the sc-2 and sc-3 compounds demonstrates a relative decrease in the ordering morphological level (Figure 7, Table 6).

\subsection{POM, SEM and AFM Morphologies}

The study of crystallization in non-isothermal conditions confirms the stereo-complexation of the compound coded as sc-1. Compared to the base-PLLA, this compound contains more small crystals in the same volume (Figure 8). The growth of a greater number of crystallites, in the same volume, was possible due to the increasing crystallization rate following the racemic nucleation after the stereo-complexation [48,49]. The crystallization in isothermal conditions reveals the same conclusion: the racemic nucleation followed the stereo-complexing because, at the same time and volume, fewer and larger small crystals appeared in the case of the base-PLLA, compared to numerous and smaller crystals for the sc-1 compound (Figure 9). According to the SEM micrographs, the stereo-complexed com- 
pound has a more ordered morphology (Figure 10). Unlike the two compounded polymers, as demonstrated by SEM micrographs, the sc- 1 blend showed crystals arranging in lamellar structures at melt processing, probably along the direction of the shear stress action.

(a)

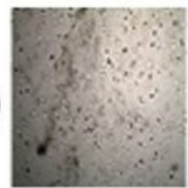

$137^{\circ} \mathrm{C}$

(b)

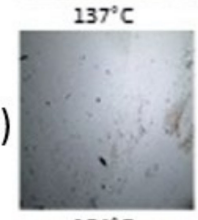

$184^{\circ} \mathrm{C}$

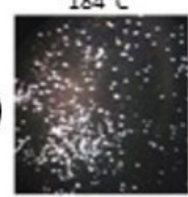

$130^{\circ} \mathrm{C}$



$125^{\circ} \mathrm{C}$

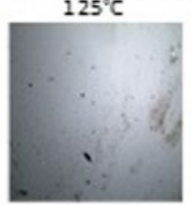

$143^{\circ} \mathrm{C}$

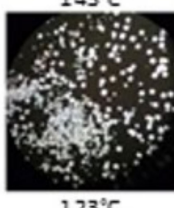

$123^{\circ} \mathrm{C}$

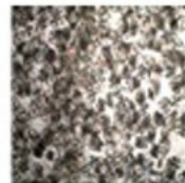

$121^{\circ} \mathrm{C}$

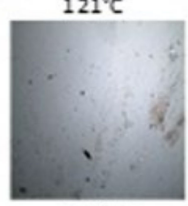

$125^{\circ} \mathrm{C}$

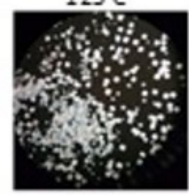

$121^{\circ} \mathrm{C}$

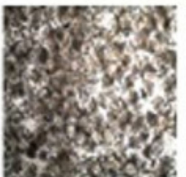

$118^{\circ} \mathrm{C}$

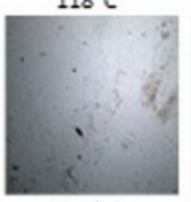

$100^{\circ} \mathrm{C}$



$119^{\circ} \mathrm{C}$

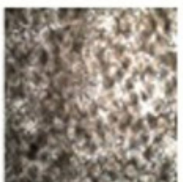

$116^{\circ} \mathrm{C}$
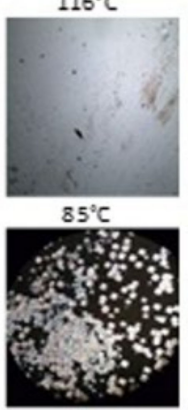

$115^{\circ} \mathrm{C}$

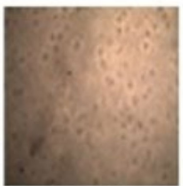

$109^{\circ} \mathrm{C}$

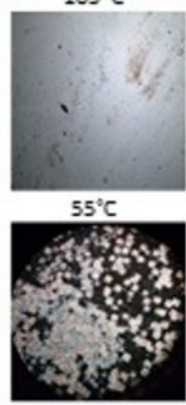

$113^{\circ} \mathrm{C}$

Figure 8. POM micrographs of $(\mathrm{a})$ base-PLLA $\left(\mathrm{P}_{\mathrm{b}}\right)(\mathbf{a})$, stereo-complexer PDLA $\left(\mathrm{P}_{\mathrm{m} 1}\right)(\mathbf{b})$ and resulting stereo-complexed compound sc-1 (c), taken during non-isothermal crystallization.

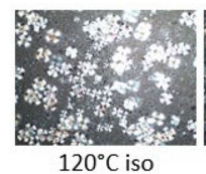

$120^{\circ} \mathrm{C}$ iso

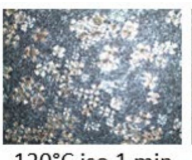

$120^{\circ} \mathrm{C}$ iso $1 \mathrm{~min}$

(a)

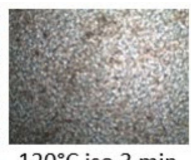

$120^{\circ} \mathrm{C}$ iso $3 \mathrm{~min}$

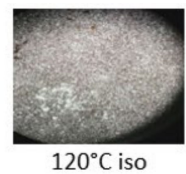

(b)

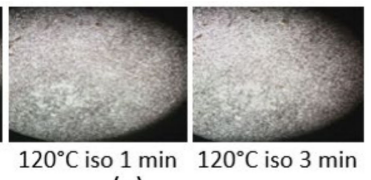

(c)

Figure 9. POM micrographs taken during isothermal crystallization, at $120^{\circ} \mathrm{C}$, of base-PLLA $\left(\mathrm{P}_{\mathrm{b}}\right)(\mathbf{a})$, stereo-complexer PDLA $\left(\mathrm{P}_{\mathrm{m} 1}\right)(\mathbf{b})$ and resulting stereo-complexed compound sc-1 (c).

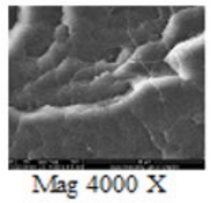

(a)

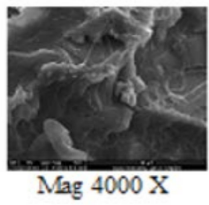

(b)

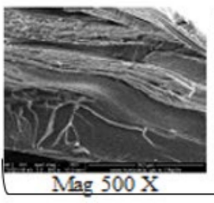

Mag $500 X$

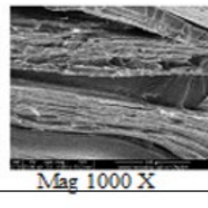

(c)

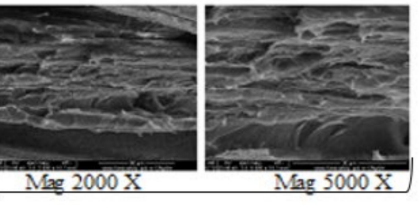

)

Figure 10. SEM micrographs base-PLLA $\left(\mathrm{P}_{\mathrm{b}}\right)(\mathbf{a})$, stereo-complexer PDLA $\left(\mathrm{P}_{\mathrm{m} 1}\right)(\mathbf{b})$ and resulting stereo-complexed compound sc-1 (c).

As shown by the parameters describing the surface roughness measured in two different areas (3D), the selected sc-1 compound has a smoother surface than that of the used PLA grades, because the roughness parameters have lower values (Table 7).

Table 7. The parameters, mean square roughness (RMS) and mean roughness (Ra) characterizing the roughness of the selected sc- 1 compound surface.

\begin{tabular}{ccccc}
\hline $\begin{array}{c}\text { Sample/ } \\
\text { Roughness } \\
\text { Parameters }\end{array}$ & \multicolumn{2}{c}{ Scanning Area (3D), $\mathbf{1} \boldsymbol{\mu m} \times \mathbf{1} \boldsymbol{\mu m}$} & \multicolumn{2}{c}{ Scanning Area (3D), $\mathbf{5} \boldsymbol{\mu m} \times \mathbf{5} \boldsymbol{\mu m}$} \\
\cline { 2 - 5 } & RMS $(\mathbf{n m})$ & $\mathbf{R}_{\mathbf{a}}(\mathbf{n m})$ & RMS $(\mathbf{n m})$ & $\mathbf{R}_{\mathbf{a}}(\mathbf{n m})$ \\
\hline $\mathrm{P}_{\mathrm{b}}$ & 4 & 3 & 10 & 7 \\
\hline $\mathrm{P}_{\mathrm{m} 1}$ & 2 & 2 & 6 & 5 \\
\hline $\mathrm{sc}-1$ & 3 & 2 & 16 & 12 \\
\hline
\end{tabular}




\subsection{Functional Properties of Stereo-Complexed PLA}

The functional properties of the selected compound sc- 1 confirmed the idea that if the base-PLLA $\left(\mathrm{M}_{\mathrm{W}}\right.$ of $\left.4.5 \times 10^{4} \mathrm{~g} \cdot \mathrm{mol}^{-1}\right)$ is modified with a PLA with medium molecular weight $\left(11.6 \times 10^{4} \mathrm{~g} \cdot \mathrm{mol}^{-1}\right)$ and medium D-lactide content $(4 \%)$, the measured functional properties are thus improved: the Izod impact resistance is $1.8 \mathrm{~kJ} / \mathrm{m}^{2}$ higher and the HDT is $17^{\circ} \mathrm{C}$ higher than the values characterizing the base-PLLA (Table 8).

Table 8. Functional properties of base-PLLA and racemic nucleated PLA.

\begin{tabular}{ccc}
\hline \multirow{2}{*}{ Specimen $\backslash$ Properties } & \multicolumn{2}{c}{ Functional Property } \\
\cline { 2 - 3 } & Izod Impact Resistance $\mathbf{( k J / \mathbf { m } ^ { \mathbf { 2 } } )}$ & HDT $\left({ }^{\circ} \mathbf{C}\right)$ \\
\hline Base-PLLA & 0.56 & 78 \\
\hline Stereo-complexed PLA (sc-1) & 2.36 & 95 \\
\hline
\end{tabular}

\subsection{Shapeability of Selected Stereo-Complexed PLA as Filaments for 3D Printing}

The selected racemic-nucleated compound (sc-1) was shaped, with good results, as filaments for 3D printing (Figure 11). These filaments had both their diameter (variation from 1.90 to $1.80 \mathrm{~mm}$ ) and their ovality in the allowed range (variation from 0.005 to $0.06 \mathrm{~mm}$ ), had smooth surfaces and no defects, and they behaved accordingly when $3 \mathrm{D}$ printed.
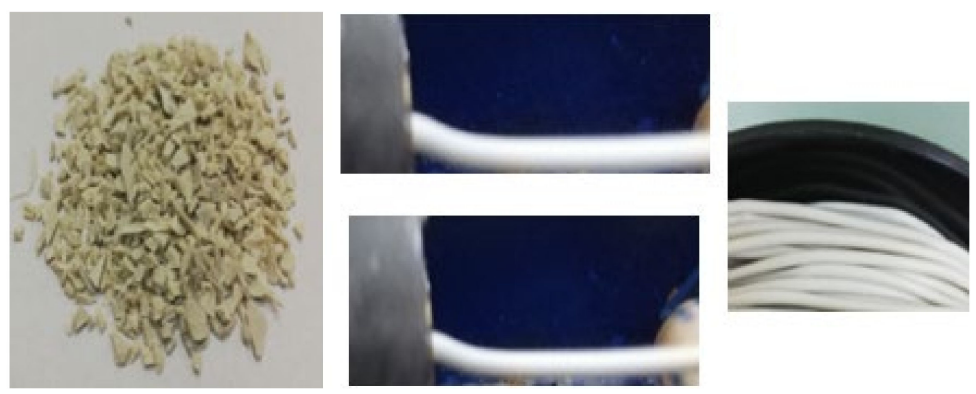

Figure 11. Shaping of selected racemic nucleated selected compound into 3D printing filaments.

\section{Discussion}

All of the obtained results reveal the dependence of the racemic nucleation on the molecular weight of the PDLA macromolecules, their DS content and the concentration of the stereo-complexer.

It is well known that relatively short macromolecules crystalize faster than the longer ones because the crystallization is diminished by their entanglement degree [50]. A medium or high DS content level can reduce the compound crystallinity because, with a great number of racemic connections between the macromolecules, the chain fragments that can be ordered by crystallization decrease. The bimodal melting observed in the case of the compounds that did not show racemic crystallization happened because during their cooling, at least two different-sized crystals appeared [51].

The racemic crystallization also depends on the concentration of the used PDLA. High concentrations do not favor racemic crystallization, because higher concentrations mean many entanglement points and, hence, few chain segments that can crystallize.

The thermal behavior of the selected sc- 1 compound sustains the idea that racemic nucleation is possible if a base-PLLA with a $\mathrm{M}_{\mathrm{w}}$ of $4.5 \times 10^{4} \mathrm{~g} \cdot \mathrm{mol}^{-1}$ is modified with a PDLA with a medium $\mathrm{M}_{\mathrm{W}}$ of $11.6 \times 10^{4} \mathrm{~g} \cdot \mathrm{mol}^{-1}$ and medium DS of $4 \%$. Consequently, the stereo-complexing effect depends not only on the length of the PDLA macromolecules and their D-lactide content but also on the concentration of the stereo-complexation modifier. All the DSC results sustain the conclusions of the FTIR study. 
A reduction in roughness is proof that the selected compound has no phase separation, is homogenous and was not degraded at melt processing [52,53]. This degradation could cause surface micro-cracking and increase surface roughness [53]. These results also confirm the stereo-complexation of the two PLA grades, and, thus, their racemic nucleation-demonstrated by POM as well as SEM- differs fundamentally from the morphologies of the melt-compounded PLA grades.

Due to the more plentiful but smaller crystallites dispersing into the amorphous matrix represented by entangled macromolecules of the stereo-complexer PDLA $\left(11.6 \times 10^{4} \mathrm{~g} \cdot \mathrm{mol}^{-1}\right.$ and DS of $4 \%$ ), the resulted more ordered semi-crystalline morphology of the selected compound seems to be much more elastic than the base-PLLA and, therefore, to need higher broken energy. The values of the functional properties prove the improvement in the thermal and mechanical behavior of the base-PLLA, with it obtaining a grade with good shapeability as $3 \mathrm{D}$ printing filaments. To have proper $3 \mathrm{D}$ printing behavior, a polymeric material must melt and crystallize in narrow temperature ranges. Melting in a narrow range means uniform flow in the molten state during shaping of selected compounds into 3D printing filament. The crystallization describes the effect of cooling on the newly achieved $3 \mathrm{D}$ printed items, as well as on its removal from the 3D printing support [13,54-56]. As was shown in Section 3.2, the selected compound meets these conditions.

Compared to the current PLA filaments on the market, those attainable by racemic crystallized PLLA have improved durability because of the following advantages: controllable 3D printing behavior and the 3D printed items no longer softening in hot summer weather and no longer breaking at the smallest stresses acting on them. The developed filaments will be used for 3D printing in the automotive industry.

The composting behavior of the racemized PLLA will not be influenced by the presence of PDLA, because, through racemization, it interacted with PLLA and lost its individual properties. It is obvious that through racemic nucleation as a result of stereocomplexing, the functional properties and durability of PLA can be controlled. However, it is still necessary to identify other parameters that control the effect of stereo-complexation so that the advantages obtained can be enlarged. To better control stereo-complexing and thus racemic crystallization, future studies should increase the mobility of the PLA macromolecules involved in stereo-complexing so that the intensity of racemic interactions is higher. Further studies will also be performed to identify the racemic crystallization window, which represents the conditions in which racemic crystallization has the most convenient intensity

This study's results showing an increase in PLA durability by racemic nucleation following stereo-complexing, and other results regarding the control of PLA crystallization by using nucleating agents [13], are part of a broader research agenda to increase the sustainability of PLA designed for 3D printing car parts.

\section{Conclusions}

The possibility of improving the functional properties of PLA by stereo-complexing of a PLA grade designed for 3D printing was studied. This PLA was melt compounded with different PLA grades, which differ in the length of the macromolecules, D-lactide content and concentration. The resulting compounds were characterized while considering structural methods (FTIR, DSC, POM, SEM and AFM) and procedures for identifying the functional properties and the shapeability of the selected compound as filaments for $3 \mathrm{D}$ printing.

All the obtained results sustain the idea that if PLLA with a $\mathrm{M}_{\mathrm{w}}$ of $4.5 \times 10^{4} \mathrm{~g} \cdot \mathrm{mol}^{-1}$ is modified with PDLA with a medium $\mathrm{M}_{\mathrm{w}}$ of $11.6 \times 10^{4} \mathrm{~g} \cdot \mathrm{mol}^{-1}$, medium DS of $4 \%$ and $1 \%$ concentration, then a racemic nucleation is possible, which would improve the functional properties

The obtained results can be explained by considering mainly the dependence of the macromolecules' interactions on their molecular weight and D-lactide content. The relatively short polymer chains form crystals more readily than long chains, because the 
crystallization is diminished by the entanglement degree of the long chains. A medium or high content D-lactide can decrease the compound crystallinity, because at a large number of racemic connections between the macromolecules, the chain fragments that can be ordered by crystallization decrease. A higher concentration of modification PDLA initiates too many racemic nucleation points, and so the stereo-complexation becomes uncontrollable.

The filaments attainable by racemic crystallization are more durable as those existing in this time on the market because of the following improved properties: better 3D printability, without softening in hot summer and breaking at regular mechanical stresses.

Author Contributions: D.D.: Conceptualization, methodology, data curation, writing-reviewing, supervision, funding acquizition, project administration; S.M.: Methodology, investigation, writing original, draft preparation, editing; M.M.I.: Methodology, investigation, draft preparation; D.I.: Methodology, investigation, draft preparation; R.T.: Methodology, investigation, draft preparation; S.I.: Methodology, investigation, draft preparation. All authors have read and agreed to the published version of the manuscript.

Funding: The work on this paper was supported by: A. Cohesion funds of the European Union POCA1- A1.2.3-G-2015- P_40-352-SECVENT 81/2016, "Sequential processes of closing the side streams from bioeconomy and innovative (bio)products resulting from it", Subsidiary project 1480/2019.B. The Government of Romania, Ministry of Research and Innovation, through projects: code PN-III-P11.2PCCDI-2017-0428, no. 40/PCCDI/2018.

Institutional Review Board Statement: Not applicable.

Informed Consent Statement: Not applicable.

Data Availability Statement: The data presented in this study are available on request from the corresponding author.

Conflicts of Interest: The authors declare no conflict of interest.

\section{References}

1. Xiao, L.; Wang, B.; Yang, G.; Gauthier, M. Poly (Lactic Acid)-based biomaterials: Synthesis, modification and applications. Biomed. Sci. Eng. Technol. 2012, 11, 247-282.

2. Refaa, Z.; Boutaous, M.; Rousset, F.; Fulchiron, R.; Zinet, M.; Xin, S.; Bourgin, P. Crystallization kinetics of Poly-(Lactic Acid) with and without talc: Optical microscopy and calorimetric analysis. AIP Conf. Proc. 2014, 1593, 342-346.

3. Nomai, J.; Suksut, B.; Schlarb, A.K. Crystallization behavior of Poly (lactic acid)/titanium dioxide nanocomposites. KMUTNB Int. J. Appl. Sci. Technol. 2015, 8, 251-258. [CrossRef]

4. Castro-Aguirre, E.; Iniguez-Franco, F.; Samsudin, H.; Fang, X.; Auras, R. Poly(lactic acid)—Mass production, processing, industrial applications, and end of life. Adv. Drug Deliv. Rev. 2016, 107, 333-366. [CrossRef]

5. Nanthananon, P.; Seadan, M.; Pivsa-Art, S.; Suttiruengwong, S. Enhanced crystallization of poly(lactic acid) through reactive aliphatic bisamide. IOP Conf. Ser. Mater. Sci. Eng. 2015, 87, 12067. [CrossRef]

6. Feng, Y.; Ma, P.; Xu, P.; Wang, R.; Dong, W.; Chen, M.; Joziasse, C. The crystallization behavior of poly(lactic acid) with different types of nucleating agents. Int. J. Biol. Macromol. 2018, 106, 955-962. [CrossRef]

7. Lim, L.T.; Auras, R.; Rubino, M. Processing technologies for poly(lactic acid). Prog. Polym. Sci. 2008, 33, 820-852. [CrossRef]

8. Liu, P.; Chen, X.-T.; Ye, H.-M. Enhancing stereocomplexation ability of Polylactide by coalescing from its inclusion complex with urea. Polymers 2017, 9, 592. [CrossRef]

9. Li, N.; Chen, J. Advances in chemical modifications of polylactide biodegradable materials. In Advances in Engineering Research, Volume 120, Proceedings of the 2017 3rd International Forum on Energy, Environment Science and Materials (IFEESM), Shenzhen, China, 25-26 November 2017; Atlantis Press: Paris, France, 2018.

10. Shi, X.; Qin, J.; Wang, L.; Ren, L.; Rong, F.; Li, D.; Wang, R.; Zhang, G. Introduction of stereocomplex crystallites of PLA for the solid and microcellular poly(lactide)/poly(butylene adipate-co-terephthalate) blends. RSC Adv. 2018, 8, 11850-11861. [CrossRef]

11. Vaes, D.; Coppens, M.; Goderis, B.; Zoetelief, W.; Van Puyvelde, P. Assessment of crystallinity development during fused filament fabrication through fast scanning chip calorimetry. Appl. Sci. 2019, 9, 2676. [CrossRef]

12. Bouzouita, A. Elaboration of polylactide-based materials for automotive application: Study of structure-process-properties interactions. Ph.D. Thesis, Université de Valenciennes et du Hainaut-Cambresis, Université de Mons, Mons, Belgium, 2016.

13. Mathe, S.; Dimonie, D.; Mariana Cristea, M. Thermal analysis and polarized light microscopy as methods to study the increasing of the durability of PLA designed for 3D printing. Int. J. Polym. Anal. Charact. 2021, 26, 253-264. [CrossRef]

14. Shao, J.; Liu, Y.-L.; Xiang, S.; Bian, X.-C.; Sun, J.-R.; Li, G.; Chen, X.-S.; Hou, H.-Q. The stereocomplex formation and phase separation of PLLA/PDLA blends with different optical purities and molecular weights. Chin. J. Polym. Sci. 2015, 33, 1713-1720. [CrossRef] 
15. Baimark, Y.; Sumet Kittipoom, S. Influence of chain-extension reaction on stereocomplexation, mechanical propertiesand heat resistance of compressed stereocomplex-Polylactide bioplastic films. Polymers 2018, 10, 1218. [CrossRef]

16. Srisuwan, Y.; Baimark, Y. Mechanical properties and heat resistance of stereocomplex polylactide/copolyester blend films prepared by in situ melt blending followed with compression molding. Heliyon 2018, 4, e01082. [CrossRef]

17. Bai, H.; Zhang, W.; Deng, H.; Zhang, Q.; Fu, Q. Control of crystal morphology in poly(L-lactide) by adding nucleating agent. Macromolecules 2011, 44, 1233-1237. [CrossRef]

18. Jia, S.; Yu, D.; Zhu, Y.; Wang, Z.; Chen, L.; Fu, L. Morphology, Crystallization and thermal behaviors of PLA-based composites: Wonderful effects of hybrid GO/PEG via dynamic impregnating. Polymers 2017, 9, 528. [CrossRef]

19. Sun, Z.; Wang, L.; Zhou, J.; Fan, X.; Xie, H.; Zhang, H.; Zhang, G.; Shi, X. Influence of Polylactide (PLA) stereocomplexation on the microstructure of PLA/PBS blends and the cell morphology of their microcellular foams. Polymers 2020, 12, 2362. [CrossRef]

20. Zhang, C.; Lan, Q.; Zhai, T.; Nie, S.; Luo, J.; Yan, W. Melt crystallization behavior and crystalline morphology of polylactide/Poly( $\varepsilon-$ caprolactone) blends compatibilized by lactide-caprolactone copolymer. Polymers 2018, 10, 1181. [CrossRef]

21. Fehri, S.; Cinelli, P.; Coltelli, M.B.; Anguillesi, I.; Lazzeri, A. Thermal properties of plasticized Poly (Lactic Acid) (PLA) containing nucleating agent. Int. J. Chem. Eng. Appl. 2016, 7, 85-88. [CrossRef]

22. Aliotta, L.; Cinelli, P.; Coltelli, M.B.; Righetti, M.C.; Gazzano, M.; Lazzeri, A. Effect of nucleating agents of crystallinity and properties of poly(lactic acid) (PLA). Eur. Polym. J. 2017, 93, 822-832. [CrossRef]

23. Anderson, K.S.; Hillmyer, M.A. Melt preparation and nucleation efficiency of polylactide stereocomplex crystallites. Polymer 2006, 47, 2030-2035. [CrossRef]

24. Kolstad, J.J. Crystallization kinetics of Poly(i-lactide-co-meso-lactide. J. Appl. Polym. Sci. 1996, 62, 1079-1091. [CrossRef]

25. Ahmed, J.; Varshney, S.K. Polylactides—chemistry, properties and green packaging technology: A review. Int. J. Food Prop. 2011, 14, 37-58. [CrossRef]

26. Han, L.; Pan, P.; Shan, G.; Bao, Y. Stereocomplex crystallization of high-molecular-weight poly(L-lactic acid)/poly(D-lactic acid) racemic blends promoted by a selective nucleator. Polymer 2015, 63, 144-153. [CrossRef]

27. Dimonie, D.; Vasile, C.; Coserea, R.M.; Garea, S.; Andrei, F. Characterization of the nucleation efficiency based on crystallization behavior and other PP properties. Mater. Plast. 2009, 46, 180-184.

28. Balanescu, G. (Ed.) Chemistry Dictionary; Tehnica: Bucuresti, Romania, 1964.

29. Eleuteri, M.; Bernal, M.; Milanesio, M.; Monticelli, O.; Fina, A. Stereocomplexation of Poly(Lactic Acid)s on graphite nanoplatelets: From functionalized nanoparticles to self-assembled nanostructures. Front. Chem. 2019, 7, 176. [CrossRef]

30. D'Ambrosio, R.M.; Michell, R.M.; Mincheva, R.; Hernández, R.; Mijangos, C.; Dubois, P.; Müller, A.J. Crystallization and stereocomplexation of PLA-mb-PBS multi-block copolymers. Polymers 2018, 10, 8. [CrossRef]

31. Farah, S.; Anderson, D.G.; Langer, R. Physical and Mechanical Properties of PLA, and Their Functions in Widespread Applications-A Comprehensive Review. Adv. Drug Deliv. Rev. 2016, 107, 367-392. [CrossRef]

32. Zhang, J.; Sato, H.; Tsuji, H.; Noda, I.; Ozaki, Y. Infrared spectroscopic study of CH3OC interaction during Poly(l-lactide)/Poly(dlactide) Stereocomplex Formation. Macromolecules 2005, 38, 1822-1828. [CrossRef]

33. Slager, J.; Domb, A.J. Biopolymer stereocomplexes. Adv. Drug Deliv. Rev. 2003, 55, 549-583. [CrossRef]

34. Li, G.; Zhao, M.; Xu, F.; Yang, B.; Li, X.; Meng, X.; Teng, L.; Sun, F.; Li, Y. Synthesis and biological application of polylactic acid. Molecules 2020, 25, 5023. [CrossRef] [PubMed]

35. Martino, V.; Ruseckaite, R.; Jiménez, A. Thermal and mechanical characterization of plasticized poly (l-lactide-co-d,l-lactide) films for food packaging. J. Therm. Anal. Calorim. 2006, 86, 707-712. [CrossRef]

36. Jing, Z.; Shi, X.; Zhang, G. Competitive stereocomplexation and homocrystallization behaviors in the Poly(lactide). blends of PLLA and PDLA-PEG-PDLA with controlled block length. Polymers 2017, 9, 107. [CrossRef] [PubMed]

37. Ahmed, R. Poly(Lactic Acid) Stereocomplex Formation in the Melt: Limitations and Prospectives. Ph.D. Thesis, Technische Universiteit Eindhoven, Eindhoven, The Netherlands, 2011.

38. Liao, J. Preparation and Modification of Thermoplastic/Tannins Composites via Reactive Extrusion. Ph.D. Thesis, Université de Lorraine, Nancy, France, 2019.

39. Meaurio, E.; López-Rodríguez, N.; Sarasua, J.R. Infrared Spectrum of Poly(L-lactide): Application to Crystallinity Studies. Macromolecules 2006, 39, 9291-9301. [CrossRef]

40. Chang, Y.; Chen, Z.; Yang, Y. Benign Fabrication of Fully Stereocomplex Polylactide with High Molecular Weights via a Thermally Induced Technique. ACS Omega 2018, 3, 7979-7984. [CrossRef]

41. Yuniarto, K.; Purwanto, Y.A.; Purwanto, S.; Welt, B.A.; Purwadaria, H.K.; Sunarti, T.C. Infrared and Raman Studies on Polylactide Acid and Polyethylene Glycol-400 Blend. AIP Conf. Proc. 2016, 1725, 020101.

42. Qiu, Z.; Li, Z. Effect of orotic acid on the crystallization kinetics and morphology of biodegradable poly(L-lactide) as an efficient nucleating agent. Ind. Eng. Chem. Res. 2011, 50, 12299-12303. [CrossRef]

43. Rudnik, E. Chapter 3-Properties and applications. In Compostable Polymer Materials, 2nd ed.; Elsevier: Amsterdam, The Netherlands, 2019; pp. 49-98.

44. Wang, Y.; He, D.; Wang, X.; Cao, W.; Li, Q.; Shen, C. Crystallization of poly(lactic acid) enhanced by phthalhydrazide as nucleation agent. Polym. Bull. 2013, 70, 2911-2922. [CrossRef] 
45. Spinelli, G.; Kotsilkova, R.; Ivanov, E.; Petrova-Doycheva, I.; Menseidov, D.; Georgiev, V.; Di Maio, R.; Silvestre, C. Effects of filament extrusion, 3D printing and hot-pressing on electrical and tensile properties of Poly(Lactic) acid composites filled with carbon nanotubes and graphene. Nanomaterials 2020, 10, 35. [CrossRef]

46. Sancaktar, E.; Gomatam, R. A study on the effects of surface roughness on the strength of single lap joints. J. Adhes. Sci. Technol. 2001, 15, 97-117. [CrossRef]

47. Hammer, A.; Fedelich, N.; Giani, S.; Hempel, E.; Jing, N. Thermal Analysis of Polymers; Mettler Toledo: Greifensee, Switzerland, 2013.

48. Jiang, L.; Shen, T.; Xu, P.; Zhao, X.; Li, X.; Dong, W.; Ma, P.; Chen, M. Crystallization modification of poly(lactide) by using nucleating agents and stereocomplexation. e-Polymers 2016, 16, 1-13. [CrossRef]

49. Kao, Y.-C. Simulation of Polymer Crystal Growth in Fused Deposition Modelling. Master's Thesis, The University of Manchester, Manchester, UK, 2018.

50. Arif, P.M.; Kalarikkal, N.; Thomas, S.; Gowd, E.B. Crystallization in Multiphase Polymer Systems; Elsevier: Amsterdam, The Netherlands, 2018; pp. 1-16.

51. Qi, L.; Zhu, Q.; Cao, D.; Liu, T.; Zhu, K.R.; Chang, K.; Gao, Q. Preparation and properties of stereocomplex of Poly(lactic acid) and its amphiphilic copolymers containing glucose groups. Polymers 2020, 12, 760. [CrossRef]

52. Muthuraj, R.; Misra, M.; Mohanty, A.K. Mohanty Biodegradable compatibilized polymer blends for packaging applications: A literature review. J. Appl. Polym. Sci. 2018, 135, 45726. [CrossRef]

53. Rapp, G.; Samuel, C.; Odent, J.; Raquez, J.-M.; Dubois, P.; Bussiere, P.-O.; Gardette, J.-L.; Therias, S. Peculiar effect of stereocomplexes on the photo chemical ageing of PLA/PMMA blends. Polym. Degrad. Stab. 2018, 150, 92-104. [CrossRef]

54. Dimonie, D.; Damian, C.; Trusca, R.; Rapa, M. Some aspects conditioning the achieving of filaments for 3D printing from physical modified corn starch. Mater. Plast. 2019, 56, 351. [CrossRef]

55. Dimonie, D.; Dragomir, N. Melt rheology of renewable polymers and of new materials based on them as tool in controlling the 3D/4D printability. Mater. Plast. 2020, 57, 77-87. [CrossRef]

56. Dimonie, D.; Dragomir, N.; Stoica, R. Attempts to diminish the drawbacks of polylactic acid designed for 3D/4D printing technology-fused deposition modeling. Mater. Plast. 2021, 58, 142-153. [CrossRef] 